\title{
USEFUL SOLUTIONS
}

\section{Dear Reader,}

Even though people complain about too many useful commercial vehicles in overcrowded cities and endless convoys of HGVs on motorways, they still want to enjoy North German beer in Bavaria and eat Bavarian yoghurt in Hamburg. This means plenty of business for haulage companies.

The latest economic figures are a clear indication of the continued success of commercial vehicle manufacturers and hauliers. "The last two years have seen a great recovery. In Western Europe, sales of heavy commercial vehicles (over six tonnes) in 2011 climbed to around 262,000 units," said VDA President Matthias Wissmann in the run-up to the $64^{\text {th }}$ IAA Commercial Vehicles, which will take place in Hanover from 20 to 27 September 2012. That is a huge rise of 31 per cent compared to 2009.

Under the slogan "Commercial Vehicles: Driving the Future", the IAA in Hanover will underline the innovative power of the industry and the efficiency of commercial vehicles. One example of state-of-the-art technology is the Mercedes-Benz Actros. This truck has been optimised in every detail from its powertrain to its rolling resistance and aerodynamics. As a result, the Euro VI version of the Actros now consumes only around 26 litres of diesel per 100 kilometres -4.5 per cent less than its Euro V compliant predecessor - in spite of lower emission levels.

Diesel emissions are today; electromobility is tomorrow. What the future state of technology might look like is shown by RTWH Aachen University in its innovative "Smart Wheels" project described on page 4 . The two institutes ika and Isea have developed an electric bus with recharging intervals that enable it to achieve the daily driving range of urban bus routes. ika produced a proto- type while Isea developed the battery system and an innovative fast charging unit.

In spite of all the euphoria surrounding technical developments and economic data, the commercial vehicle industry is nevertheless feeling the impact of the national debt crisis in European countries. The VDA expects new registrations of heavy trucks in Western Europe to total between 256,000 and 250,000 over the year 2012. That would be a drop of two to four per cent compared to the previous year. Looking beyond Europe, Brazil will also see a fall in its figures due to the introduction of a new exhaust standard and economic factors. China is having a break from expansion this year with a slight drop of three per cent.

Careful planning is therefore the order of the day. But one thing is certain: the IAA, with more exhibitors and a larger area than 2010, will have the right answers and will present useful solutions for the transport market of today and tomorrow.

Best regards,

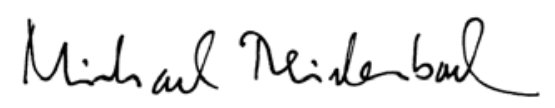

DIPL.-ING. MICHAEL REICHENBACH,

Vice-Editor in Chief

Wiesbaden, 7 August 2012

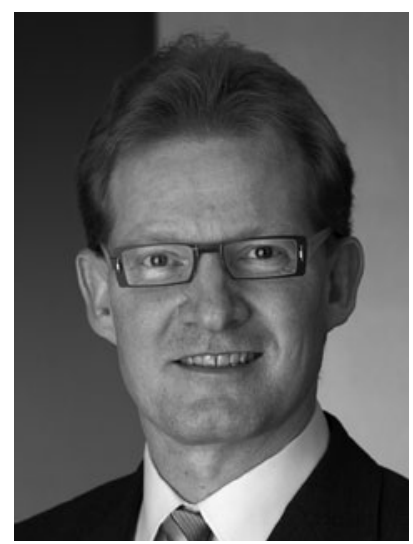

